\title{
The Metabolism of Insects-II
}

\author{
Successive Changes Undergone During Their Post-Embryonic Lives
}

By August Lameere, Professor in the University of Brussels

Concluded from Scientific American Supplement No. 2124, Page 179, September 16, 1916

VIII.

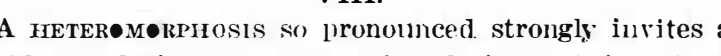
highly revolutionary process of evolution to bring about the disapearance of the larval organs-a complicate metamorphosis, involving an extendell period of repos to compensate for the long delay in the formation of the adult.

The holometabolian larva, after its penultimate casting, gorged with the food reserve accumulated in its adipose tissue, is transformed into an inactive nymph like the pupae of the scales, but presenting externally almost the appearance of the imago. It has the eye the antennae, the legs and the wings of the adult. The imaginal disks corresplonding to these organs have reached this development during the last period of th larval life, but their evolution is nevertheless far from larval life, but their evolution is nevertheless far frow
terminated. The nymph has overtaken and passed the prosopon, being now comparable to the last stage of adolescence of a paurometabolic insect, or even to the sub-imago of the ephemerids.

What goes on inside during this time? Two concomitant phenomena: the destruction of the larval organs and the formation of the definitive insect. The more specialized of the larval organs atrophy completely more specialized of the larval organs atrophy completely digestive tube, which is expelled bodily. The muscula organization is partially destroyed by a process of histolysis. This is aided by tiny globules of blood, concerning whose precise rôle students have not yet bee able to agree, but which are known to contain the elements that go to form the imaginal muscular structure. On the other hand, the organs peculiar to the adult-the genital apparatus, the eyes, and the ap adult-the genital apparatus, the eyes, and the ap
pendages, as well as the new lining of the digestive tract-are built up at the expense of the pre-existing "outline sketches" mentioned above. Finally the remain ing organs-heart, nervous system and Malpighian tube -are supplied by various means. The reserve albuminoids of the adipose bodies are utilized in part for the nutrition of the tissues in the course of evolution

The exact biological cause governing metamor phosis is unknown to us. Many hypotheses have been put forward, but none give complete satisfaction. We can in any event agree that the competition of the imagina organs places the larval organs at a physiological disadvantage which contributes to the destruction of the latter; but what the excitant is that causes the passage of the larva into the pupa we cannot say. We sometimes observe that in a given lot of caterpillars somo will become chrysalides at the expected time, while others persist in passing through the winter to trans form themselves in the following year. Why? Per haps, as Rabaud suggests, there would here be a field for experimental research.

$$
\text { IX. }
$$

It is not sufficient to explain how the caterpillar becomes the butterfly, it is equally necessary to attempt the discovery of how the butterfly disguises himself as a caterpillar. Metamorphosis is merely a consequence of heteromorphosis, and it is of the latter that the origin should be sought. On this point we can only construct hypotheses, paleontology being unable, at least for the present, to clear up the matter for us; but it is in any event something to feel that the problem is correctly stated.

We have seen that the holometabolian larva has not attained, at the time of birth, the stage of prosopon. Consequently we should be led to expect that at its primordial origin it must have issued from the egg in a state more or less embryonic. It is necessary to inquire under what circumstances of environment such a radical innovation could have been favorable to the animal, and what would have been the primitive adaptations and what would have been the primitive adaptations
corresponding to the acquisition of these heteromorphic corresponding to the acquisition of these heteromorphic
characteristics; for the raison d'etre of a characteristie is its utility to the organism under given conditions of existence.

The problem is very simple for the heterometabolians; the larvae of the amphibious members of this group are adapted to aquatic life, those of the cicadas to subterranean existence, those of the scales to a sedensubterranean existence, those of the scale
tary existence as external plant parasites.

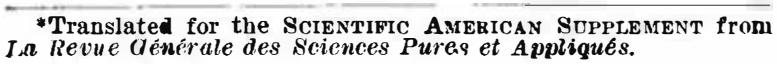

Now the holometabolians have in their first stages very diverse habits, and yet their larvae present the entire collection of original characteristics which we recognize for this group of insects. This has led to the long-standing supposition that the group wa monogenetic. Handlirsch is of a different opinion. He asserts, on paleontological grounds, that the Neurop. tera, the Coleoptera, the Panorpidae and the Hymenop tera are descended from four distinct heterometabolians. But the writer has been able, by more minute consultation of the fossil evidence, to refute this assertion and to show that all the holometabolians go back to a single type, probably the Megasectoptera, upper Carboniferou Insects first classified by Brongniart.

What, then, ought the habits of the primeval holometabolic larva to have been? This animal, of embryonic constitution, with short legs and thin skin fearing the sun and seeing poorly, was not made for a vagabond career. From his birth he had to find, In a more or. less damp environment, a shelter and an abundant source of nutrition. He therefore cannot have been a carnivorous hunter over wide expanses. But if aquatic, he would not have lost his facet eyes; if a subterranean dweller, he would not have had short subterranean dweller, he would not have had short have been; and if an external plant parasite, he would have been a suctorian. But he can only have been an internal parasite upon the plant in which his mother had deposited him as an egg. He seems indeed to have dwelt within the trunks of the Cycadaceae; this is the hypothesis which we have held since 1892 .

There he would find an early appearance [speaking geologically] possible; for there he viould have a damp shelter and the food for which his very simple digestive tract fitted him. He required only short appendages and myopic eyes; it was to his advantage to preserve throughout his growth the worm-like form in which he had been born, without any external approach to the adult state to put him in a state of progressive inferiority, and without any external wing-growth to inconvenience him and to get entangled in his close quarters.

There is, as regards the matter of habits, a strikin contrast between the heterometabolians and the holometabolians. While an immense number of the latte are found as internal parasites upon both animals and vegetables, the former always live outdoors. (It is necessary to except from this statement the white ants, for while they in general bore into tree trunks, their sexless members are truly apteral.)

The internally parasitic existence of the larvae of these primitive holometabolians, as Henneguy remarks, should apparently have been sufficient to check the acquisition of the adult characteristics and the undergoing of metamorphosis. If all our conclusions are correct, this would be almost the only endoparasite in which definite degeneration is not found; for outside certain crustacean copepods, the Monstrilla, we know of few similar examples. But then the holometabolians are the only parasites possessing wings, an incomparable means of dispersion which even the Ichneumonidae have retained.

The first holometabolian hexapods having been found in Triassic deposits, Handlirsch has attributed the origin of their metabolism to perturbations brought upon insect life by the glacial period of the Permian epoch. which caused the disappearance of so many of the heterometabolians. He looks upon the larval state as an adaptation to secure a rapid and intense alimentation, and the pupae as a means of preservation against the cold. The writer does not understand just how atmospheric influence could well have led to the acquisition by the larvae of characteristics so very special. and he would point out that the insect does not always pass through the hard season in the form of a pupa. It must be admitted, however, that this hypothesis of phytic habits adopted by the holometabolians would assure them an advantage over the heterometabolians in resisting the vicissitudes of the extreme climate.

$$
\mathrm{X} .
$$
We have seen that the transformations of the pauro-
metabolic insects may progress to hemimetabolism, to neometabolism, or to holometabolism, and that they may likewise degenerate to apometabolism. We recognize, too, an evolution from holometabolism, sometimes by complication, sometimes, on the contrary, by degeneration.

That excellent observer of insect habits, Fabre, has given the name hypermetamorphosis to the group of multiple post-emlryonic phenomena exhibited by the Coleoptera of the family of vesicant parasites Meloidae. From the egg emerges a first emigrant larva, the triongulin, which, after locating a deposit of food or eggs belonging to another insect, transforms itself into a second larva of sedentary habits. When the latter has attained its full measure of growth it passes into a state of inactivity, the pseudo-chrysalis, from which later emerges a third larva, differing but little from the second. It is only after all this that the pups stage is reached.

Now this is really no hypermetamorphosis at all, for the pseudo-chrysalis is in no way comparable to $a$ pupa. It presents none of the phenomena of histolysis; moment of repose in the post-embryonic evolution, quite analogous to the winter sleep of certain caterpillars. Whether this stage is followed by a casting or not, it comes back to the same thing; and the third larva is in fact the same as the second. What is of importance is the fact of double heteromorphosis, the triongulin being a new adaptation of the larva, a sort of larva of the true larva.

This is hypermetabolism, a term again applicable to all the other cases, as for example that of the Mantispa, where a holometabolic insect presents successive larval states adapted to different environments.

On the other hand, there is to be found among man: holometabolians a certain simplification of the evolutiol process. The insect then becomes apteral. This simplification goes to even greater lengths when the aui. mal, comparably with the female caterpillar, gives over its metamorphosis and reproduces from the larval form, which it then maintains throughout its existence. This phenomenon is also exhibited by the females of certain Coleoptera of the family Lampyridae.

Finally, we have an altogether extraordinary case in the I'ermitoxeniinae, iptera of the family Muscidae, which by a climax of originality are hermaphroditesa phenomenon unique among insects. These amazing little motes are the domestic animals of the white ants, who gather and consume a substance that oozes from the excessively swelled abdomen of their "oxen." The latter have their wings transformed into hooks by means of which their masters transport them from place to place. From the relatively large egg of these creatures the perfect insect issues directly.

We have here cryptometalolism, the last worl in insect phenomena. We may well repeat, with Linnaleus, "Natura maxime miranda in minimis."

\section{An Artillery Chronoscope}

The ordinary stop watch, or chronoscope, has a bal ance that beats fifths of a second, and as this controls the hand one fifth of a second is the smallest realing that can be had on this kind of an instrument. This, however, has been found too long an interval when iming the fight of a projectile, as it may correspon to 400 feet, which would make artillery fire based on such timing decidedly inaccurate in range. To meet this condition a London maker has produced a chronograph giving beats of a hundred to the second.

There are two ways in which this chronograph can be used. The first is the obvious one of taking the time between the firing of the gun and the explosion of the shell, the setting of the fuses can be checked; also by thus checking the range the condition of the gun can be noted. The other use is for getting the correct range of the guns of the enemy by noting tne flash of their guns and the time it takes for the sound to reach the observer. It is then possible to accurately calculate the range of the hostile battery. Extremely nice workmanship was necessary to make a watch that could be started and stopped in the hundresth part of a second repeatedly and accurately. 